\title{
Índios Kariri: o grafismo do artefato para a criação de uma fonte tipográfica digital
}

Kariri Indians: the graphics of the artifact for the creation of a digital typeface

SILVA, Rosemary Severo da I Bacharel em Design Gráfico

Universidade Federal do Cariri - UFCA I rosemarysevero02@gmail.com

LEVY, Aglaíze Damasceno I Mestre em Artes Visuais

Universidade Federal do Cariri - UFCA I aglaize.damasceno@ufca.edu.br

\begin{abstract}
Resumo
Este trabalho é um breve estudo histórico dos Índios Kariri, resgatando alguns mitos, lendas e fragmentos da arte cerâmica, somados à pesquisa bibliográfica e visual de caracteres tipográficos. A metodologia está baseada na pesquisa de elaboração de tipos e na observação de fotografias dos objetos indígenas feitas no Memorial do Homem Kariri em Nova Olinda CE. O processo criativo apresenta os exercícios desenvolvidos resultando no desenho de uma fonte tipográfica digital.
\end{abstract}

Palavras-chave: Índios Kariri. Processo criativo. Arte gráfica. Tipografia.

\section{Abstract}

This work is a brief historical study of the Kariri Indians - including their myths, legends and pottery art fragments - in addition to the bibliographic and visual research of typographic characters. The methodology is based on the research of development of types and the observation of photos of indigenous objects took at the Memorial do Homem Kariri in Northeast Brazil. The creative process includes drafting and sketching, thus resulting in the design of a digital typeface.

Key words: Kariri Indians. Creative process. Graphic art. Typography. 


\section{INTRODUC̣ÃO}

A Região do Cariri Cearense, localizada no nordeste do Brasil, é formada por vinte e sete municípios. Em Crato, Juazeiro do Norte e Nova Olinda, que compõem a Região Metropolitana do Cariri Cearense, foram encontradas as principais referências gráficas e bibliográficas, base para o desenvolvimento deste projeto.

Os Índios Kariri Novos, um dos grupos que ocuparam a Região Nordeste do Brasil, habitaram o sul do Ceará. Após o massacre ocorrido durante a Confederação dos Kariri, entre 1683 e 1713, os Índios sobreviventes foram designados para a Missão do Miranda, hoje conhecido como município do Crato.

Pesquisando o contexto histórico do Cariri, os vestígios de vida e cultura material deixado pelos povos que habitaram a região, foi desenvolvido um trabalho que, além da abordagem histórica, dispõe de um projeto gráfico a partir do estudo de um objeto de origem Índios Kariri: uma vasilha cerâmica com um desenho talhado em seu interior, encontrada no município de Barbalha e exposta no Memorial do Homem Kariri em Nova Olinda - CE'. Registros com o significado do desenho não foram identificados, mas em um catálogo do Memorial do Homem Kariri descreve-se esse artefato como de uso ritualístico. De toda forma, a investigação a respeito da temática e das referências visuais encontradas prosseguiram (MEMORIAL DO HOMEM KARIRI, 2015).

A escolha da temática e do design gráfico se deu pelo interesse em representar a região através da linguagem gráfica verbal, com a construção de caracteres tipográficos que refletem o objeto Kariri estudado. Com esse foco buscamos elementos que oferecessem possibilidades criativas no campo do Design. Dentre tantos elementos e possibilidades, o elemento gráfico presente na vasilha cerâmica foi escolhido por oferecer no desenho bidimensional forma e conteúdo com potência para desdobramentos visuais. Esse vem sendo estudado, também, de forma a afirmar que é possível a elaboração de um projeto de Design a partir de materiais, desenhos e símbolos deixados pelos Índios e da história do lugar em que o observador reside.

O trabalho teve como objetivo geral desenvolver uma fonte tipográfica digital baseada no estudo do elemento gráfico de uma vasilha cerâmica de origem Kariri, encontrada no município de Barbalha. Os objetivos específicos são: a) Realizar um breve estudo histórico dos Índios Kariri, investigando a

1 A princípio chamada de Tapera, Nova Olinda recebeu esse 'novo' nome por um missionário pernambucano, em razão do seu aspecto geográfico. Pertencente ao município de Santana do Cariri o então povoado passou à categoria de distrito, por força do decreto № 1.256, de 4 de dezembro de 1933. Nova Olinda foi elevada a município, pela lei no 3.555, de 14 de março de 1957 e instalado no dia 26 de abril do mesmo ano (IBGE, 2015). 
origem do nome, suas características, costumes e o que produziam; b) Mapear as metodologias de desenvolvimento de famílias tipográficas com a escolha de uma que melhor se adeque ao nosso objetivo de projeto; c) Mapear e analisar os objetos/utensílios de uso cotidiano ou de rituais dos Índios Kariri, presentes no Memorial do Homem Kariri, a fim de selecionar aqueles que mais apresentam configurações gráficas pintadas ou esculpidas; d) Analisar os grafismos presentes nos objetos Kariri selecionados a fim de explorar o potencial criativo, e fazer uma ponte com o design gráfico contemporâneo de fontes digitais.

A seguir, o referencial teórico está fundamentado nos conceitos e falas de autores que retratam o tema e baseando-se em suas concepções e no conhecimento adquirido, relata-se o procedimento metodológico utilizado para o processo criativo.

\section{BREVE HISTÓRICO DOS KARIRI NO NORDESTE}

Registros escritos com o histórico do povo Kariri são poucos e de restrito acesso. Nos vestígios de cultura material, como exemplo os sítios arqueológicos, foram encontradas vasilhas cerâmica, urnas funerárias, cachimbos, desenhos rupestres, pedras, dentre outros objetos "em áreas de grande beleza paisagística, como no sopé da Chapada do Araripe, oriundos de várias épocas e, como tudo indica, de populações diferentes" (LIMA et al., 2010, p. 8). Diante da limitação bibliográfica, algumas perguntas com o intuito de descobrir sobre a cultura do povo Kariri, origem do nome e como chegaram a região, por exemplo, foram imprescindíveis para guiar este trabalho. Quem eram essas pessoas que habitavam a região do Cariri Cearense? Que costumes/ valores constituíam seu estilo de vida? Que artefatos produziam e por quê?

O Cariri Cearense, segundo Figueiredo Filho (2010, p. 5), "oferece uma feição original e bem caracterizada", podemos considerar sua geografia, seus aspectos sociais, origens e etnias. Poucos têm noção da riqueza deixada pelos Índios Kariri e aqui se vem fazer um resgate dessa cultura e desse povo. A região, destaca Lima et al. (2010, p. 8), recebia muitos grupos nômades e o nome Kariri habitualmente era dado para esse povo que se deslocava até aqui, portanto "o lugar passou a ser conhecido como Cariri".

No que tange as características e costumes dos Índios Kariri, Barroso (2004, p. 53) os descreve do seguinte modo: "escuros, altos, membrudos, ornados de penas negras, carrancudos e tristonhos, figuram nos documentos antigos com vários nomes de Carirys, Carirés, Kiriris e até Alarves." Os Kariri viviam ou se deslocavam pelas ribeiras sertanejas do Ceará até próximo do litoral, de outubro a novembro, para a colheita do caju, do qual produziam o vinho chamado de mocororó (BARROSO, 2004, p. 54). 
Diante das tentativas dos portugueses colonizadores, de 'dominar' os índios, muitas vezes as tribos realizavam movimentos de resistência para não serem escravizadas ou perderem suas terras, cultivos, crenças e tradições, isso não foi diferente no Nordeste, com os Kariri. Entre 1683 e 1713, com 30 anos de duração, ocorreu a Confederação dos Cariris, que se deu pela revolta indígena em não se deixar dominar pelo homem branco, e perder suas terras. Apesar da luta contra os invasores, Barroso (2004, p. 54) afirma que os Kariri foram escravizados, maltratados, massacrados e dispersados para outras populações. Alencar (2014, p. 32) ressalta que "alguns dos remanescentes foram alocados na Missão de Miranda, onde continuaram cultivando, silenciosamente, suas crenças e tradições". A Missão de Miranda foi um aldeamento fundado por frei Carlos Maria de Ferrara e em 1764 se tornou a vila que originou a cidade de Crato (ALENCAR, 2014, p. 32). O Cariri, conhecido pelas terras férteis, propiciou a geração da atividade agrícola onde a cana-de-açúcar, encontrada até hoje, foi um dos vários gêneros alimentícios produzidos (LIMA et al., 2010, p. 08).

Em torno da segunda metade do séc. XVII, Lima et al. (2010, p. 8) aponta que a Chapada do Araripe foi povoada, dos séculos XVII a XX, várias vilas se emanciparam e "foram responsáveis pela primeira etapa da história econômica social e política da região do Cariri cearense". As vilas, hoje municípios, compõem a Região Metropolitana do Cariri, dentre elas: Crato (1764), Jardim (1814), Barbalha (1846), Missão Velha (1864), Santana do Cariri (1885), Juazeiro do Norte (1911) e Nova Olinda (1957).

A partir de registros escritos dispostos na Fundação Casa Grande Memorial do Homem Kariri ([20--]), situada em Nova Olinda, os Índios da Região Nordeste estão divididos em três grupos: Kariri Velhos - parte oriental na Chapada da Borborema; Kariri-de-fora - do centro da Bahia ao oeste de Pernambuco; Kariri Novos - do Sul Cearense no entorno da Chapada do Araripe, seus vales e afluentes. Os Kariri que habitaram o Ceará eram chamados: Kariú, Kará, Kalabaça, Icozinhos, Kixeréu, Inhamum, Jucá, Moritize, Umã, Xocó, Inxú.

\section{ALGUNS MITOS E LENDAS DOS KARIRI}

Os mitos e lendas dos Índios Kariri, também encontrados no Memorial do Homem Kariri, são histórias ligadas à água e às pedras. Para reforçar a riqueza da cultura Kariri, abaixo estão descritos dois mitos e lendas, narrativas deixadas pelos Índios com histórias da natureza da região. Estes também contribuíram na escolha das palavras que nortearam o processo criativo e consequentemente no resultado deste trabalho. 
A Pedra da Batateira: "Todas as águas que jorram de dentro da Chapada do Araripe vem do lago encantado. No dia em que a mãe d'água se levantar de sua cama e subir de nascente acima, rolarão três pedras que formam a Pedra da Batateira e toda região será inundada, transformando o sertão em mar" (MEMORIAL DO HOMEM CARIRI, [20--]).

O Castelo Encantado: "Quando o mar cobriu o sertão, encantou um castelo com todo o seu reinado, povo, jardins, pontes, deuses. Vez por outra este castelo reaparece no tempo, trazendo toda a sua riqueza e esplendor. Aquele que nele entrar e das coisas dele fizer uso, se encantará junto com ele, sumindo para sempre no portal do tempo" (MEMORIAL DO HOMEM CARIRI, [20--]).

Essas histórias fazem parte da infância dos caririenses e por isso, também, a importância de trazer este registro para o trabalho. Os mitos e lendas estão contidos no resultado do projeto, na poética de cada linha, curva, na abordagem da cultura local.

\section{FRAGMENTOS DA ARTE CERAMISTA DOS KARIRI}

Os Índios Kariri, com a intenção de suprir suas necessidades domésticas, ritualísticas e artísticas, construíram artefatos cerâmicos. No Memorial do Homem Kariri ([20--]), pode-se ver a descrição desses utensílios cerâmicos nos quais "são encontrados adornos artísticos talhados com figuras geométricas e adornos artísticos pintados nas cores: vermelho, amarelo, marrom, preto e branco". Deste modo, Limaverde (2006, p. 45) descreve artefatos "objetos feitos pelo homem, seus instrumentos de trabalho, de caça, pesca, vasilhas etc." Os artefatos podem ser estruturas "como construções, casas, abrigos, depósitos de alimentos" ou ecofatos "que são coisas da natureza usadas pelo homem, [...] restos de alimentos, ossos, pedras, carvão etc."

Após observar as peças de arte cerâmica, apresentadas na Figura 1, respectivamente, duas Urnas funerárias (I e II) e dois artefatos Cerâmicos Policroma Kariri (III e IV) ; a vasilha cerâmica da Figura 2, Cerâmica policroma para uso ritualístico, chamou atenção em relação as demais pelo desenho talhado no interior de sua superfície, apresentando forma orgânica, linhas nas cores vermelho e preto que dão movimento ao desenho. 
Figura 1 - Utensílios/artefatos doméstico e/ou de rituais Kariri $2,3,4,5$

।

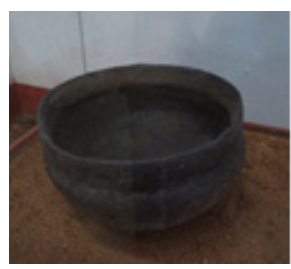

II

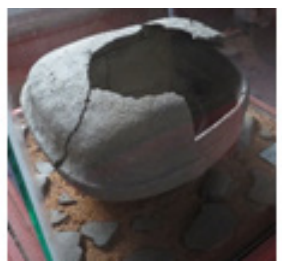

III

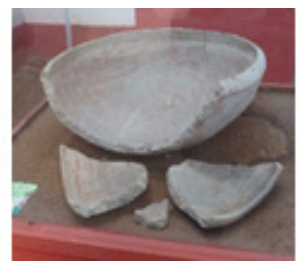

IV

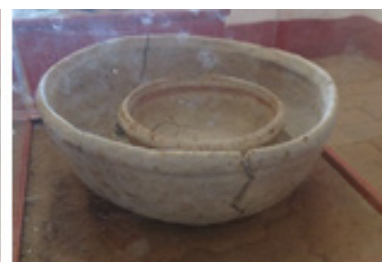

Fonte: Arquivo próprio, abril, 2015.

Figura 2 - Cerâmica policroma para uso ritualístico

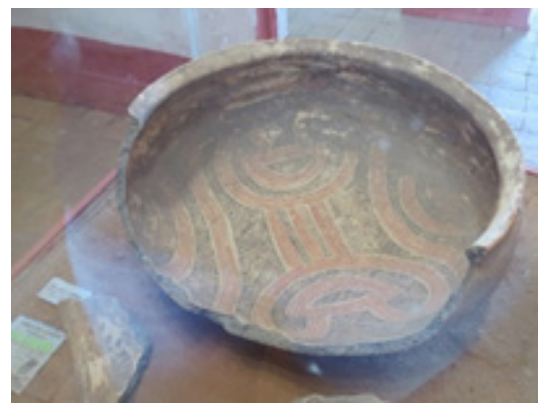

Fonte: Elaborado pelo autor, em pesquisa realizada (2014)

A seguir, considera-se as definições de Tipografia, Lettering e Caligrafia. Essa seção se faz importante para compreender melhor sobre o objeto de estudo, apresentando o contexto histórico sobre representação da escrita, a composição do tipo, critérios ergonômicos de usabilidade e classificação das famílias tipográficas.

\section{TIPOGRAFIA, LETTERING, CALIGRAFIA}

A representação visual escrita "começou a existir no momento em que desenhos ou sinais surgiram relacionados diretamente com as sílabas, palavras ou frases pronunciadas" (FRUTIGER, 2007, p. 87). A escrita propriamente dita

2 I-Procedência: Encontrada em 2003 no Sítio Chabocão, às margens do Rio Salgado pelo Sr. Francisco Pereira do Nascimento. Dimensões: Diâmetro 84 cm; Altura 14 cm. (LIMAVERDE, 2006):

3 II - Procedência: Encontrada em uma olaria no Sitio Mata, Crato, CE. Doada por Lucíola Bezerra Primo. Dimensões: Diâmetro 1m 44 cm; Altura 24 cm. (LIMAVERDE, 2006).

4 III - Encontrada no Sítio Tabuleiro, município de Altaneira - CE. Doação: Sr. Itinho. (MEMORIAL DO HOMEM CARIRI, [20--]);

$5 \quad$ IV - Encontrada no Sítio Tabuleiro, município de Altaneira - CE. Doação: Sr. Itinho. (MEMORIAL DO HOMEM CARIRI, [20--]). Procedência: Encontrada por um tratorista em uma caixa de empréstimo da Fábrica de Cimento Nassau, Município de Barbalha, Ce. Doação de Magnum Coelho. Classificação: Cerâmica policroma para uso ritualístico. Dimensões: Diâmetro $1 \mathrm{~m}$ e $30 \mathrm{~cm}$; Altura $12 \mathrm{~cm}$. (LIMAVERDE, 2006). 
surgiu com a organização do alinhamento "dos sinais lado a lado ou um sobre o outro, correspondendo à evolução linear dos seus pensamentos", sendo a escrita contínua desenvolvida gradativamente (FRUTIGER, 2007, p. 87).

Pensando na representação visual da escrita e na proposta de desenvolver uma fonte tipográfica digital, viu-se a necessidade de apontar a distinção entre as formas da linguagem gráfica verbal: tipografia, lettering e caligrafia.

Caligrafia, do grego kallos "beleza" e graphos "escrita", é "a arte de dar forma a caracteres de uma maneira expressiva, harmoniosa e habilidosa" (FINIZOLA, 2010, p. 43). O termo caligrafia utilizado para traduzir a palavra 'calligraphy', se refere "à técnica milenar de traçar letras à mão de acordo com estilos caligráficos específicos - itálico, gótico, uncial, etc." (FINIZOLA, 2010, p. 40). Na escrita manual, a construção e a formalização acontecem simultaneamente, as letras não vão ter necessariamente uma separação rígida, enquanto que na tipografia há a fragmentação na composição pois as palavras e frases são compostas pela unidade mínima, a letra (GOMES, 2010, p. 23). A idealização da forma e uso, na tipografia, acontecem em momentos distintos, "o que demanda a racionalização do processo produtivo" (GOMES, 2010, p. 23).

Figura 3 - Exemplo de caligrafia

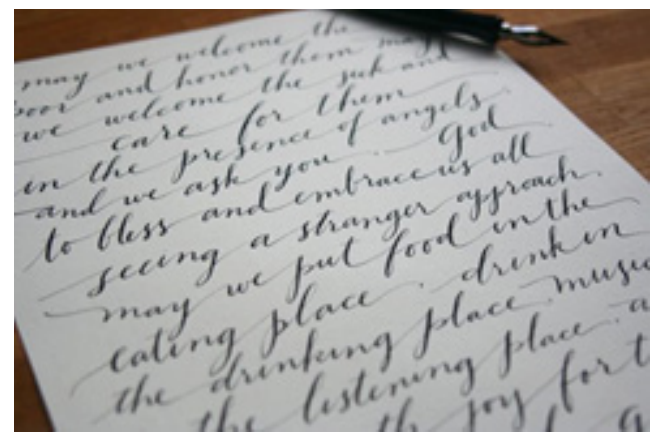

Fonte: Pinterest (2016).

O termo Lettering que pode ser traduzida por letreiramento, corresponde a "técnica de desenhar e construir conjuntos de letras por processo manual, mas que atualmente também pode ser desenvolvida por processos digitais" (FINIZOLA, 2010, p. 40). Lettering são letras desenhadas (drawn letters) "cujas partes significativas são feitas com mais de um traço" (SMEIJERS apud GOMES, 2010, p. 20). A tipografia e o lettering têm mais características em comum do que a caligrafia, "pois, em grande parte dos trabalhos de letreiramento, as formas das letras parecem muito com os tipos de impressão", mas o espacejamento e alinhamento do letreiramento são feitos manualmente e isso é que o diferencia da tipografia (SMEIJERS apud GOMES, 2010, p. 20). 
Figura 4 - Exemplo de Lettering
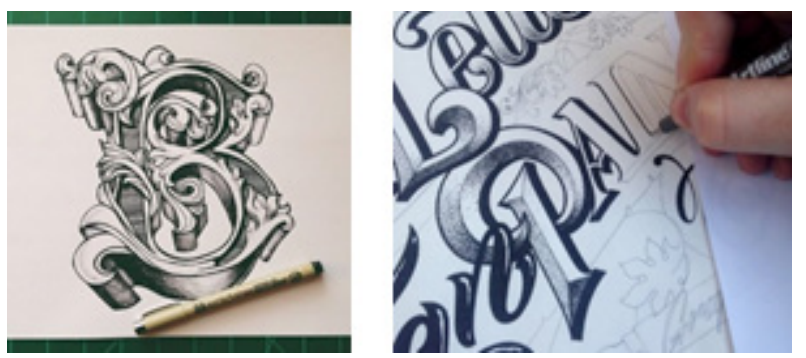

Fonte: Pinterest (2016).

O termo Tipografia, do grego Typos - Marca ou Impressão e Graphé Escrita, "surgiu em referência a arte de compor e imprimir com tipos móveis" (SOUZA, 2014). Atualmente, devido ao estudo aprofundado e produção em 'massa', o termo "se refere ao conjunto de caracteres, estilos, formatos, tamanho e arranjo visual" (SOUZA, 2014).

Figura 5 - Exemplo de tipografia - tipos móveis e família tipográfica.

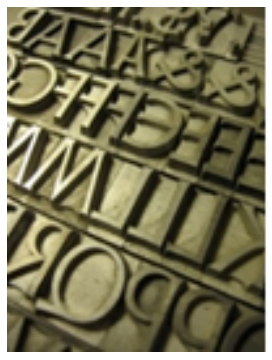

Helvetica Neue 25 Uitra Light
Helvetica Neue 35 Thin
Helvetica Neue 45 Light
Helvetica Neue 55 Roman
Helvetica Neue 65 Medium
Helvetica Neue 75 Bold
Helvetica Neue 85 Heavy
Helvetica Neue 95 Black

Fonte: Pinterest (2016).

Conforme Ambrose e Harris (2009, p. 57) "a tipografia dá o tom a uma parte do texto", quando optamos por uma determinada fonte devemos refletir se ela é adequada para a mensagem que se quer passar e para o público que irá receber essa informação, e "embora não existam regras fixas" deve-se observar os aspectos técnicos que irão facilitar a escolha dessa fonte. "A tipografia pode produzir um efeito neutro ou despertar paixões, simbolizar movimentos artísticos, políticos ou filosóficos ou exprimir a personalidade de uma pessoa ou organização" (AMBROSE; HARRIS, 2009, p. 57).

Além de transmitir o conceito proposto, de acordo com a temática escolhida, o tipo precisa seguir alguns conceitos básicos de acordo com as regras de utilização. Niemeyer (2006, p. 82) nos apresenta os três critérios ergonômicos de usabilidade do tipo: legibilidade, leiturabilidade (readability) e pregnância. Busca-se neste projeto a legibilidade e leiturabilidade dos caracteres desenhados com o intuito de usá-los em cartazes, estampas, dentre outras aplicações em que o público possa fazer uma leitura fácil da fonte tipográfica. 
A pregnância, segundo Sanders e McCormick (1993 apud NIEMEYER, 2006, p. 85) "é a qualidade de um caractere ou símbolo que faz com que ele seja visível separadamente do seu entorno." A legibilidade de um caractere individual e de um texto impresso é diferente, no sentido em que um texto longo precisa ter uma leitura prática e fácil para que o leitor não canse com a primeira frase, por exemplo, explica Niemeyer (2006, p. 82). Os 'graus de legibilidade' também dependem do que o designer quer apresentar, a utilização do tipo em uma ou algumas palavras, frases, texto corrido. A leiturabilidade, para Sanders e McCormick (1993 apud NIEMEYER, 2006, p. 84), permite identificar o "conteúdo da informação em um suporte quando ela está representada por caracteres alfanuméricos em grupamentos com significação, como palavras, frases ou texto corrido", esse discernimento depende do espaço dado entre grupos e/de caracteres, "de sua combinação em frases ou sob outras formas, do espacejamento entre linhas, do comprimento de linha e das margens, mais do que da configuração específica do caractere em si". Os termos leiturabilidade e legibilidade muitas vezes são usados de forma equivocada, sua diferença pode ser entendida do seguinte modo: um texto com pouca legibilidade terá a leiturabilidade baixa, porém se o texto não tiver boa leiturabilidade, o inverso, ele pode ser extremamente legível (NIEMEYER, 2006, p. 84).

Figura 6 - Exemplo de legibilidade alta e baixa

\section{Fonte tipográfica digital heVEetca RegULAR > Legibilidade alta}

\section{Fonte tipográfica difital MISTRAL > Legibilidade baixa}

Fonte: Adaptado de Faccione Filho (2016).

Figura 7: I - Exemplo de alta leiturabilidade e legibilidade; II Exemplo de alta leiturabilidade e baixa legibilidade; III - Exemplo de baixa leiturabilidade com uma fonte de alta legibilidade

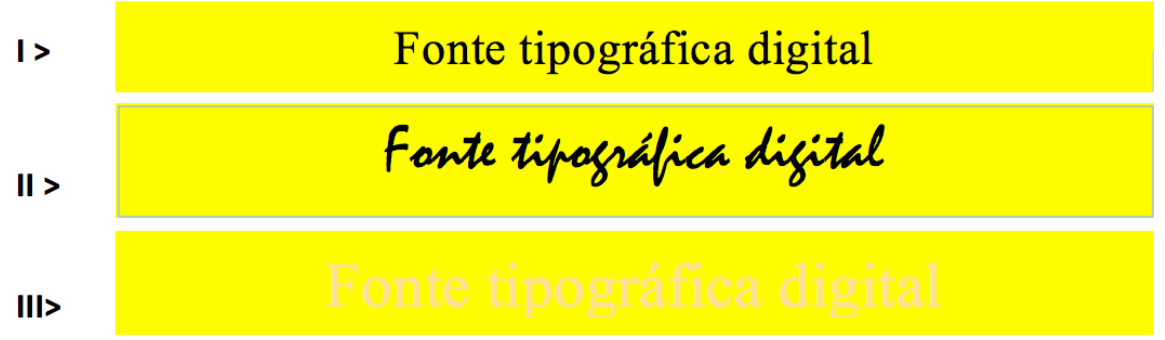

Fonte: Adaptado de Faccione Filho (2016).

Família tipográfica, segundo Niemeyer (2006, p. 16), é o conjunto de caracteres que contém características específicas em comum. Horcades (2004, p. 15), da mesma forma destaca: "letras também devem ser parecidas; todas as 
letras de um alfabeto devem apresentar o mesmo estilo e grafismo. Por isso, chamamos alfabetos de famílias". Ambrose e Harris (2009, p. 118), ressaltam "uma família tipográfica compreende todas as variações de uma determinada fonte, incluindo os diferentes pesos, larguras e itálicos".

O tipo é composto por algumas partes principais, Niemeyer (2006, p. 34) os apresenta: "hastes (linhas verticais), barras (horizontais), barrigas e bojos (curvas ou circulares), ascendentes e descendentes, montanhas, ápices e vértices, serifas e esporas, ocos". Niemeyer (2006, p. 34) ainda destaca "nenhum caractere possui todos esses elementos - e há outros específicos (braços, ombros, ganchos, orelhas etc.)".

\section{Figura 8 - Partes do tipo}
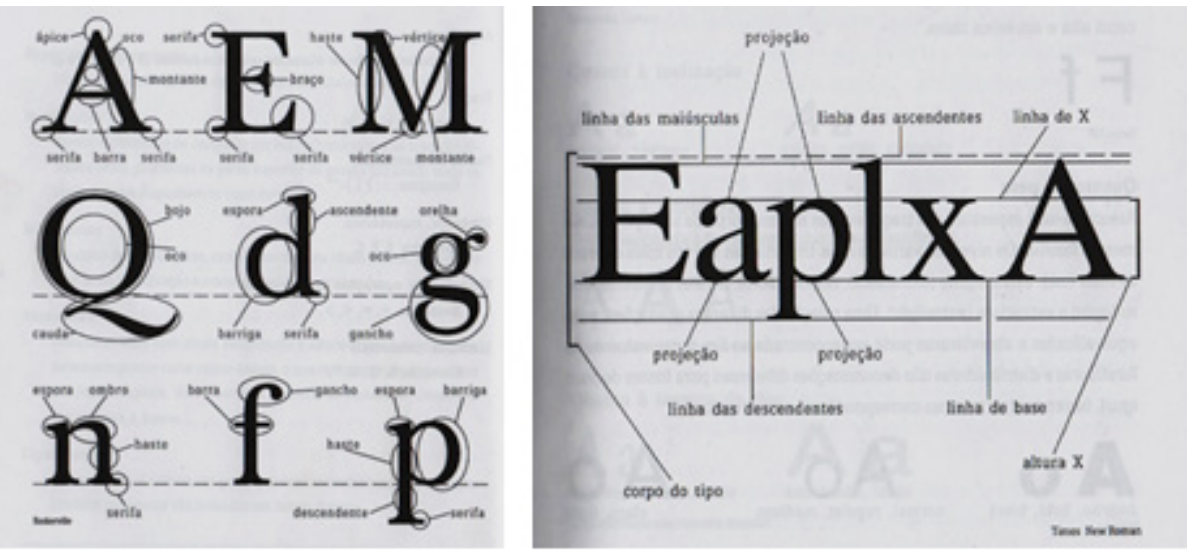

Fonte: Niemeyer (2006, p. 34).

Figura 9 - Variações estruturais do tipo

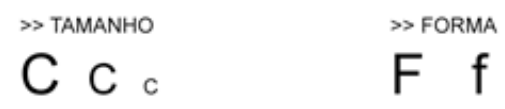

> PESO

\begin{tabular}{|c|c|}
\hline 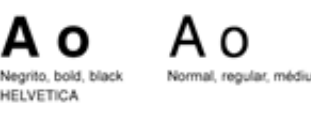 & 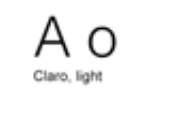 \\
\hline 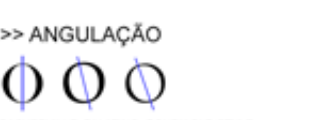 & $\begin{array}{l}\gg \text { ESPESSURA } \\
\mathrm{A} \quad \mathrm{A}\end{array}$ \\
\hline A $\mathrm{A} A \mathrm{INCLNAG \overline {O } O}$ & $\begin{array}{l}\text { > ESTRUTURA } \\
\text { A A }\end{array}$ \\
\hline
\end{tabular}

> LARGURA

$\underset{\text { Hevencha Conoensed }}{\text { A } 0}$

Tamanho: altura do corpo do tipo;

Forma: diferenças no desenho do caractere em caixa alta e baixa;

Peso: se refere a espessura dos traços dos caracteres de uma mesma família tipográfica;

Contraste: angulação e espessura do traço;

Inclinação: normal, romano, itálico, grifo, inclinado;

Estrutura: se refere à que família o tipo está classificado;

Largura: condensado, apertado, expandido, largo. 
Índios Kariri: o grafismo do artefato para a criação de uma fonte tipográfica digital

O grande número de desenhos de tipos levou as famílias tipográficas a serem agrupadas de acordo com suas características em comum. A divisão de sete classes, com suas subclasses, foi adotada pela Association Typographique Internationale (ATypl), conhecida como Classificação Tipográfica Vox/ATypl (NIEMEYER, 2006, p. 50) são elas: Romanos: humanistas ou venezianos; garaldos/garaldo-aldinos ou garaldinos; transicionais/de transição/barrocos ou old style; didones ou modernos; mecanizados; Lineares ou sem serifa: grotescos; geométricos; neogrotescos; humanísticos; Incisos; Manuais: decorativos, de display ou fantasia; brush; Manuscritos ou Script; Góticos: texturados; rotundos; bastardos; Franktur e variantes Franktur; Não Latinos.

Dentro das características acima citadas a respeito da estrutura e composição dos tipos, o grupo de caracteres desenvolvida neste projeto, na seção resultados, será analisada e classificada em quanto família tipográfica.

\section{METODOLOGIA}

O estudo histórico dos Índios Kariri foi realizado através da pesquisa bibliográfica e relato de alguns estudiosos. As referências visuais sobre a temática foram encontradas no Memorial do Homem Kariri - Fundação Casa Grande localizada em Nova Olinda-CE, em visita feita em abril de 2015. O local dispõe de vários artefatos, utensílios, pedras, urnas funerárias, cachimbos, mitos, lendas e registros fotográficos de sítios com pinturas rupestres desenvolvidos pelo povo Kariri. Os objetos dispostos no local foram fotografados, priorizando suas posições onde a visualização dos desenhos e formas eram valorizadas. As referências sobre metodologias de elaboração e princípios básicos para a construção tipográfica se deram prioritariamente a partir da leitura dos artigos desenvolvidos por professores e alunos do Laboratório de Tipografia do Agreste do Centro Acadêmico do Agreste da UFPE', as referências visuais foram pesquisadas principalmente na rede social Pinterest ${ }^{7}$, no site Lettering vs Calligraphy, entre outros.

A metodologia do desenho de caracteres tipográficos foi uma junção do processo criativo utilizado para desenvolver uma coleção de joias, que foi a primeira proposta de projeto pensada a partir da temática, mas por conta da atuação no design gráfico o projeto foi reestruturado considerando a elaboração

5 O Laboratório de Tipografia do Agreste (LTA) é um espaço concebido para conjugar atividades de ensino e pesquisa tipográficas na Universidade Federal de Pernambuco (UFPE), Campus de Caruaru, interior do Nordeste. Através da mobilização de professores e alunos de design envolvidos no programa de interiorização do ensino da UFPE, esse laboratório pretende trazer para a região discussões sobre desenho de tipos, emprego de fontes e famílias tipográficas, impressão com tipos móveis, produção e encadernação de livros, caligrafia e história da escrita (LABORATÓRIO DE TIPOGRAFIA DO AGRESTE, 2016).

6 Pinterest é uma rede social e ferramenta visual onde se pode favoritar, compartilhar, salvar e fazer upload de fotos. Nele se pode criar murais, armazenar referencias visuais e portfólio (PINTEREST, 2016).

Projética, Londrina, v.8, n.2, p. 29-50, Jul./Dez. 2017 
de uma fonte tipográfica digital. A experimentação de formas somada aos materiais e técnicas foram baseadas nas descrições de Martins, Buggy e Vieira (2012) em seu artigo 'Compilação de métodos para desenho tipográfico usados por designers recifenses', chamadas de Modifying Type e Tracing Scans, ambas são apresentadas por Leslie Cabarga no livro Logo, Font \& Lettering Bible (CABARGA, 2004) e estão entre as 5 (cinco) técnicas práticas do desenho tipográfico.

No método Modifying Type, dentro do processo de criação, uma fonte pré-existente é modificada para que o designer desenhe seu próprio alfabeto (MARTINS; BUGGY; VIEIRA, 2012). Portanto, essa metodologia foi inserida dentro do processo criativo desenvolvido: escolha de tema $>$ pesquisa de referências $>$ escolha de objeto/elemento gráfico > reprodução do elemento gráfico > experimentação de formas e materiais > rabisco de letras à mão em A4 > rabisco de letras à mão em papel vegetal $>$ desenho vetorial do elemento gráfico > escolha de fonte base > edição de fonte base: vetor + fonte base.

Já no Tracing Scans, Martins, Buggy e Vieira (2012) explanam que o desenho dos caracteres é digitalizado e vetorizado, pois algumas correções muitas vezes são necessárias, já que o desenho é feito à mão. Enfatizam ainda que o designer "tem a opção de usar o software para vetorizar o desenho". Assim sendo, o segundo processo desenvolvido junto a essa metodologia foi: escolha de tema $>$ pesquisa de referências > escolha de objeto/elemento gráfico > reprodução do elemento gráfico > rabisco de letras > digitalização > correção dos caracteres desenhados.

A metodologia do processo criativo do produto final foi: escolha de tema $>$ pesquisa de referências > escolha de objeto/elemento gráfico > reprodução do elemento gráfico > estudo do desenho - linha e preenchimento > rabisco de letras à mão em A4 > rabisco de letras em papel quadriculado > rabisco de letras em papel vegetal > digitalização > vetorização e correção de caracteres.

\subsection{Processo Criativo}

O processo criativo é um componente muito importante para a continuação dos estudos dos vestígios e cultura material deixados pelo povo Kariri. Os desdobramentos visuais desenvolvidos vêm do desenho, nas cores preto, vermelho e branco (Figura 10), encontrado no interior da vasilha cerâmica Kariri.

Figura 10: Vasilha de cerâmica encontrada em Barbalha - CE

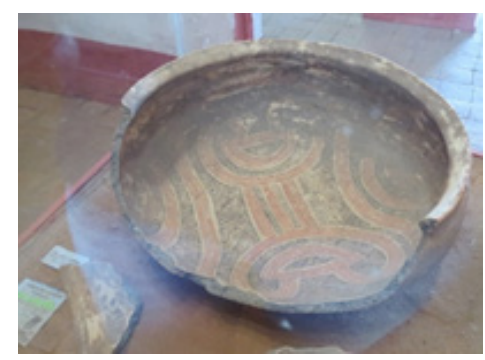

Fonte: Arquivo próprio, abril, 2015.

Projética, Londrina, v.8, n.2, p. 29-50, Jul./Dez. 2017 
Este trabalho se propõe a explorar o desenho de origem Kariri apresentado na Figura 10. Levando em conta a experimentação, e o próprio processo criativo aqui exposto, Lupton e Phillips (2008, p. 10) discorrem que o experimento é o procedimento onde se analisa a "forma, material ou processo no sentido metódico, ainda que abertos", nele isolamos elementos, "limitando algumas variáveis a fim de melhor estudar outras". Destacam ainda que no experimento "levanta uma questão ou testa uma hipótese cuja resposta não é conhecida de antemão."

Dentro do processo de criação as primeiras atividades executadas foram: pontuar as características dos utensílios Kariri; listagem de 10 (dez) palavras relacionadas a temática; escolha de um ou mais objetos/elementos para traçar os primeiros desenhos, explorando formas e materiais; fotocópia dos desenhos, com ampliações e reduções. Segue, nesta mesma ordem, as etapas descritas:

I - Palavras listadas: As palavras elencadas fizeram parte de um exercício do qual a finalidade era que elas falassem por si a respeito da temática. Então, a partir das características dos Índios encontradas em referências bibliográficas e da observação feita dos objetos expostos no Memorial do Homem Kariri, se fez uma lista de palavras (o máximo possível) e foram selecionadas as 10 (dez) que de fato condiziam com o propósito, são elas: fazer manual, cultura material, artefato, cerâmica, utensílio, processo, elemento gráfico, singularidade, delicadeza, adorno.

Il - Desenho - estudo da forma: A reprodução do desenho original encontrado no objeto Kariri foi o segundo exercício para iniciar o processo de experimentação de formas, materiais e texturas. Logo após, os desdobramentos com as formas positivo e negativo ${ }^{7}$ do desenho Kariri, estudos de linha, experimentação da forma em papeis diversos.

Figura 11 - Experimentações: I - Desenho de observação, hidrocor sobre papel kraft; II - Primeiras variações do desenho com preenchimento da forma (positivo), hidrocor sobre papel vegetal
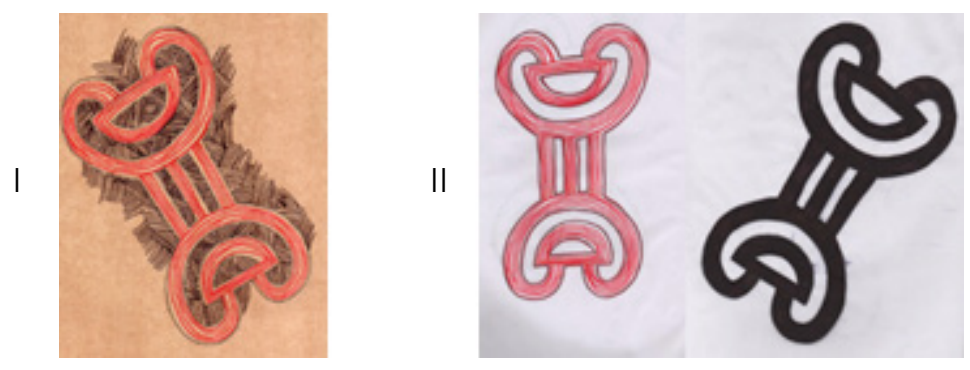

Fonte: Arquivo próprio, 2015.

7 A forma é geralmente apreendida como espaço ocupado, mas também pode ser vista como um espaço vazio circundado por espaço ocupado. Quando é percebida como ocupando um espaço, nós a chamamos forma "positiva". Quando é percebida como um espaço vazio circundado por espaço ocupado, nós a chamamos forma "negativa". (WONG, 2010, p. 47).

Projética, Londrina, v.8, n.2, p. 29-50, Jul./Dez. 2017 
Figura 12 - Experimentações: I - Desdobramentos com preenchimento negativo, hidrocor sobre papel vegetal; II -

Desdobramentos - estudo da linha
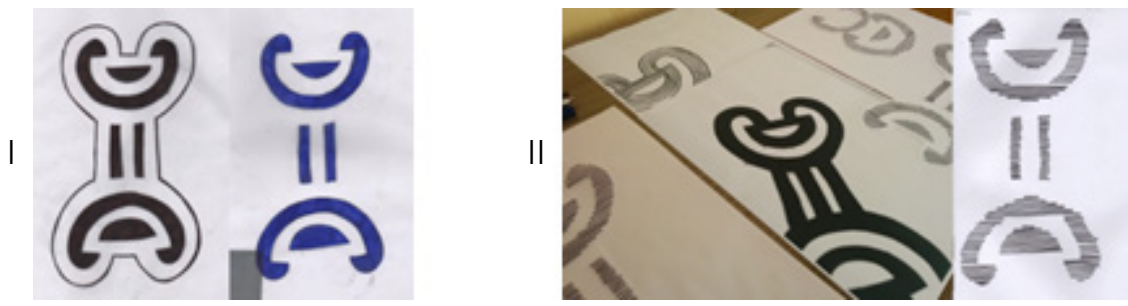

Fonte: Arquivo próprio, 2015.

Após os experimentos de linha, o desenho Kariri foi reproduzido novamente, desconstruído e ganhou formas 2D e 3D.

Figura 13 - Experimentação de formas - desconstrução dos elementos, estudo 3D e 2D
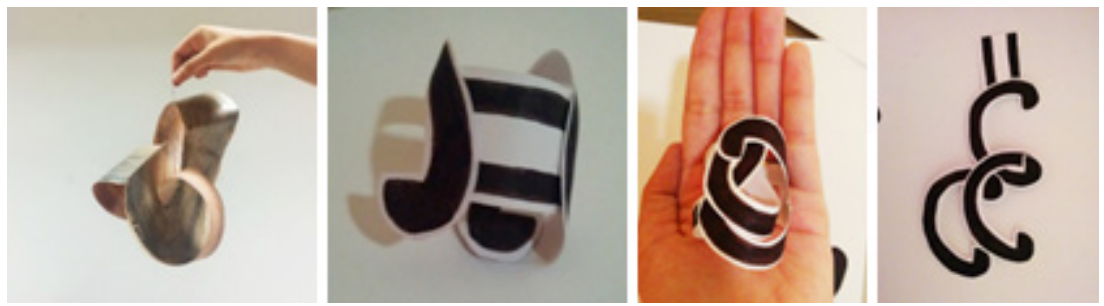

Fonte: Arquivo próprio, 2015.

Pensando na singularidade do desenho e na forma como se deu o processo criativo, os caracteres foram elaborados a partir dos estudos a seguir (Figura 14), a escolha pela forma negativa com o acompanhamento da linha que circunda o espaço positivo.

Figura 14: I - Estudo do desenho - preenchimento das formas e contornos, espaços positivo e negativo; II - Formas selecionadas para o estudo do desenho de caracteres

I

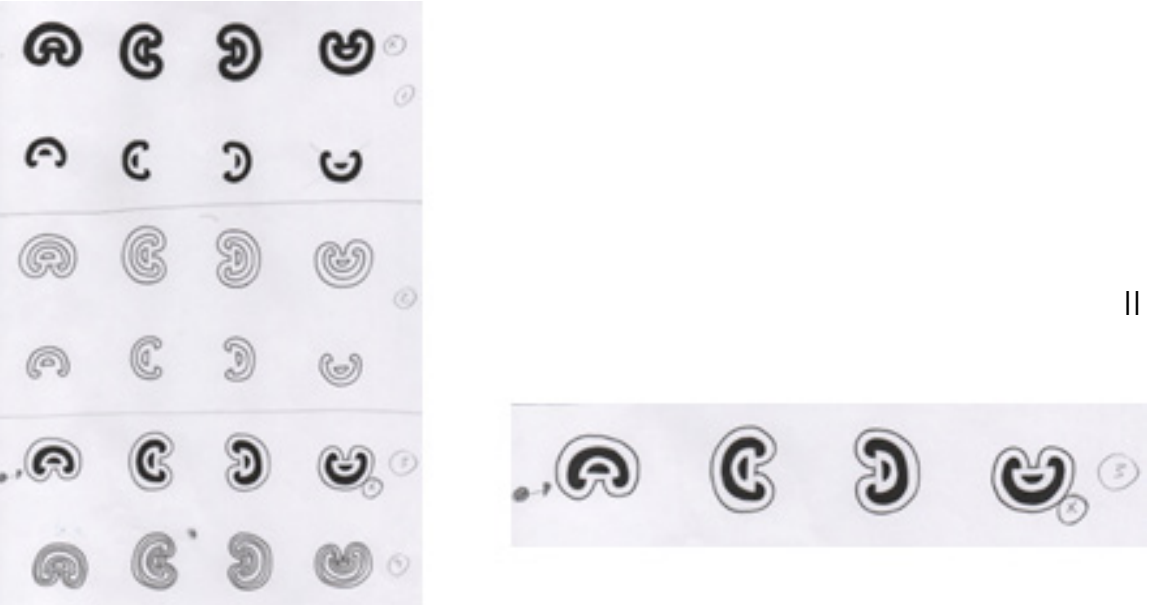

Fonte: Arquivo próprio, 2015. 
Figura 15 - I - Desenho de caracteres - papel quadriculado; II Desenho de caracteres - papel vegetal

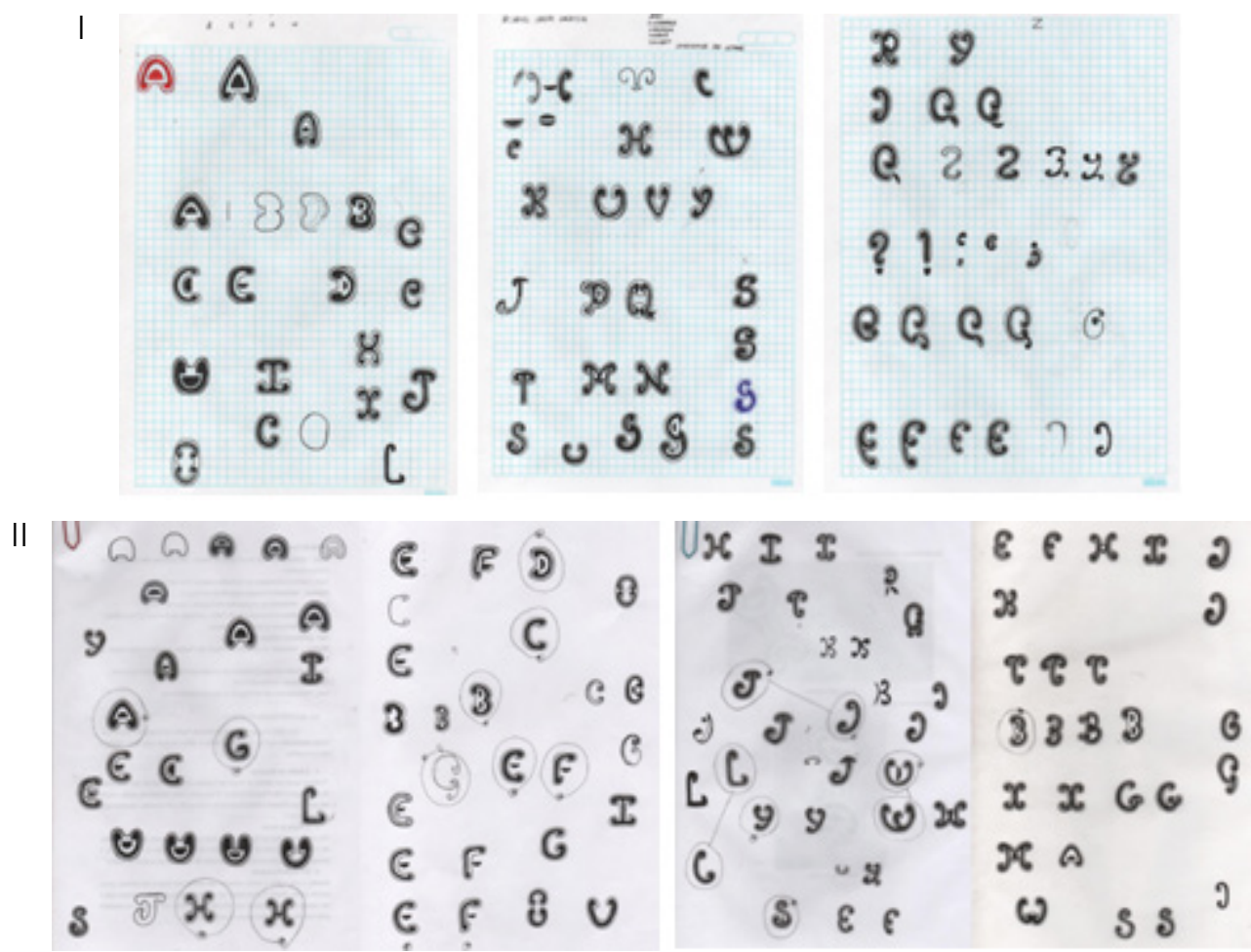

Fonte: Arquivo próprio, 2015.

\section{RESULTADOS}

Considerando o referencial teórico e a pesquisa feita sobre tipografia, somada à metodologia e processo criativo, tem-se como resultado a linguagem gráfica verbal de uma fonte tipográfica digital, partindo do desenho de origem Kariri.

A fonte tipográfica enquanto estrutura está classificada como Manual Decorativa. Geralmente esses caracteres, não se destinam a texto corrido, são utilizados em logotipos, displays, cartazes, posters, anuncios publicitários (NIEMEYER, 2006, p. 62). As variações estruturais: quanto a forma, são caracteres em caixa alta; peso, a espessura dos traços são regular e apresenta o estudo em outline; inclinação normal. A seguir apresenta-se o resultado desse projeto.

Figura 16 - Desenho vetorial da forma apresentada na figura 14

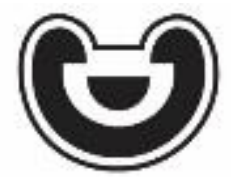

Fonte: Elaborada pela autora, 2016 
Figura 17 - Desenho vetorial dos caracteres - Regular

\section{A $3 \subset D \in F G H$ I J ICLA $D$ C Q R S T U U U $x$ Y 2 Ç}

Fonte: Elaborada pela autora, 2016.

Figura 18 - Desenho vetorial dos caracteres - Outline

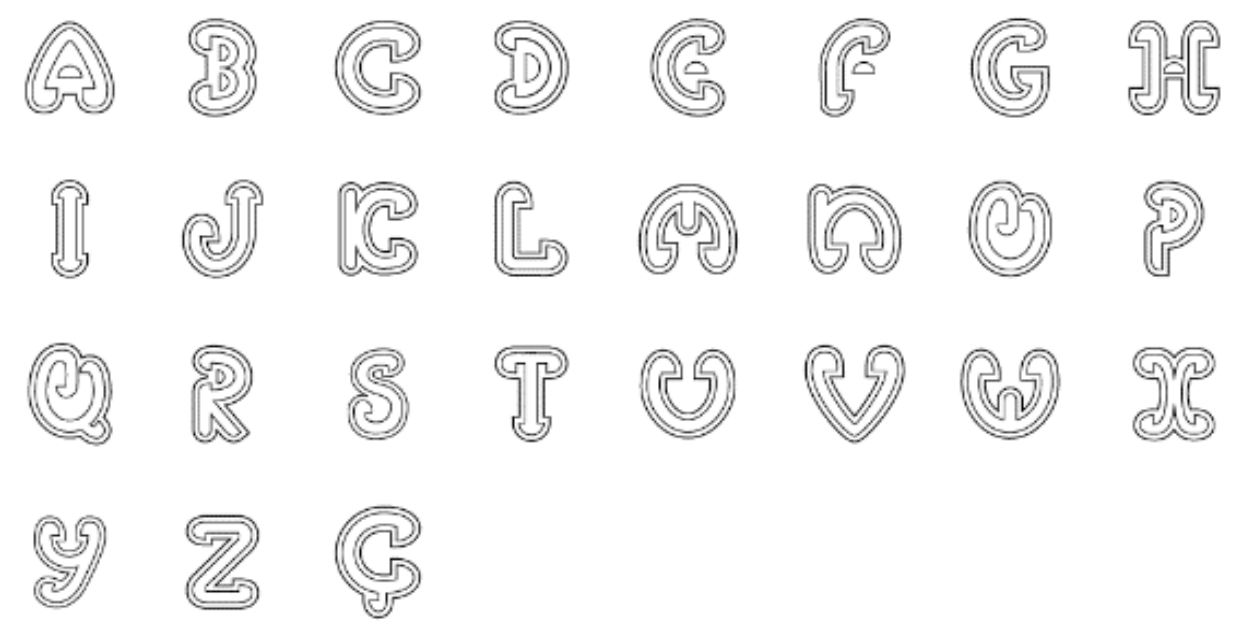

Fonte: Elaborada pela autora, 2016.

Os caracteres tipográficos foram desenhados em grupos, e a partir da forma de uma letra as outras foram desenvolvidas. Os caracteres estão divididos em quatro grupos. A letra ' $D$ ', forma vetorial do desenho Kariri mostrado na Figura 16, com rotação de 90ำ para a esquerda, foi a base principal para a elaboração dos caracteres. Devido a angulação e desenho da forma de cada letra, além do 'D', algumas outras letras auxiliaram as demais.

Figura 19 - Grupo de caracteres 01

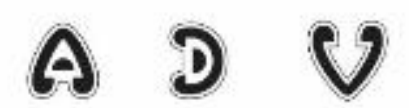

Fonte: Elaborada pela autora, 2016. 
A distorção dos ângulos no desenho de 'B' auxiliaram as formas das letras ' $P$ ' e ' $R$ '. Na figura abaixo, as hastes que compõem as duas letras ganham destaque para mostrar sua configuração e contorno.

Figura 20 - Grupo de caracteres 02

\section{(B) $D \rightarrow ?$}

Fonte: Elaborada pela autora, 2016.

O grupo de caracteres abaixo tiveram como base (secundária) a letra 'C', e a letra ' $M$ ' foi eixo para ' $N$ ' e ' $W$ '.

Figura 21 - Grupo de caracteres 03

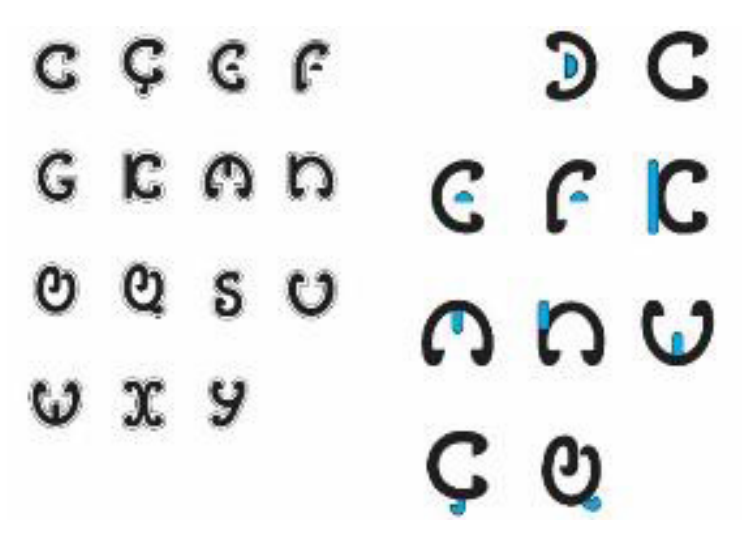

Fonte: Elaborada pela autora, 2016.

O grupo abaixo teve apoio de ' $\mathrm{H}$ ', as hastes da letra, com alguns ajustes, puderam ser utilizadas nas demais ' $I$ ', 'J', ' $L$ ', 'T' e 'Z'.

Figura 22: Grupo de caracteres 04

\section{] I I J L T Z ] I $\int \mathrm{C}$}

Fonte: Elaborada pela autora, 2016.

\subsection{Testes de Escrita}

Figura 23: Teste de escrita - municípios da Região Metropolitana do Cariri

\section{JUAZGIRO BARBAL]-[A \\ CRATO DOUA OLIDDA}

Fonte: Elaborada pela autora, 2016.

Projética, Londrina, v.8, n.2, p. 29-50, Jul./Dez. 2017 


\subsection{Aplicações}

A seguir, sublinhando a função prática da fonte tipográfica, apresentamse aplicações em camiseta e cartaz eletrônico projetando possíveis produtos e a usabilidade dos caracteres. A estampa com a grafia 'Ôxe', expressão muito utilizada no Nordeste, foi desenvolvida para o Cariri Criativo Convida, ação da Feira Cariri Criativo $^{8}$ onde um artista ou designer é convidado a cada mês para elaborar uma estampa.

Figura 24 - Estampa desenvolvida, para o Cariri Criativo Convida
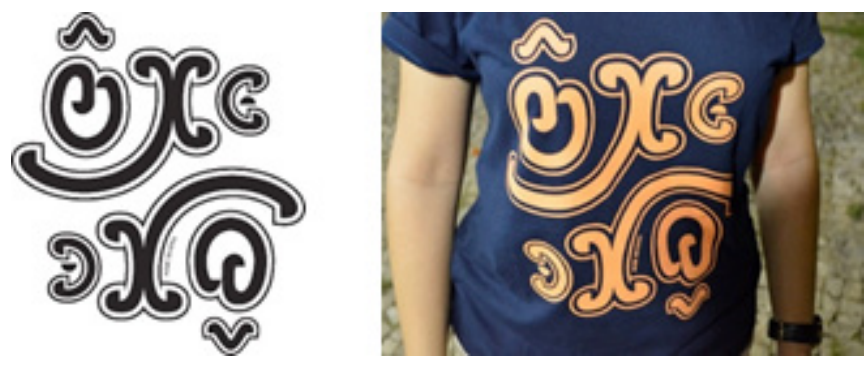

Fonte: Elaborada pela autora, 2016.

Figura 25 - Cartaz eletrônico de divulgação da estampa

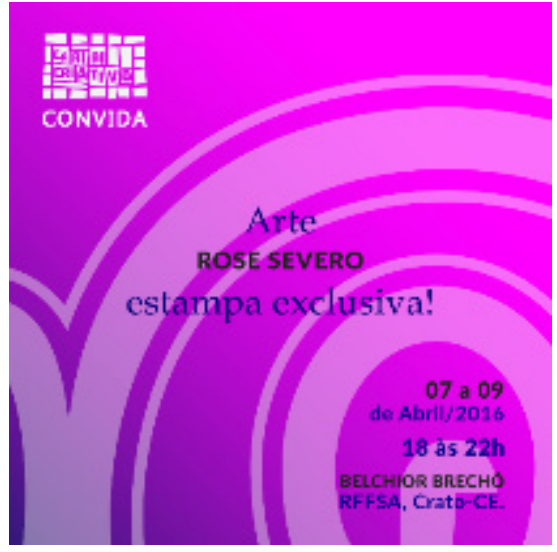

Fonte: Elaborada pela autora, 2016.

8 A Feira Cariri Criativo é uma realização da Universidade Federal do Cariri através do Programa de Fomento à Economia Criativa Do Cariri. Mensalmente, no segundo final de semana de cada mês, a Feira reúne empreendedores criativos, grupos e coletivos de cultura e arte e organizações ligadas ao tema da Economia Criativa no Cariri Cearense e ainda possui programação cultural durante os três dias. (CARIRI CRIATIVO). 
Figura 26 - Aplicação em ecobags e agenda
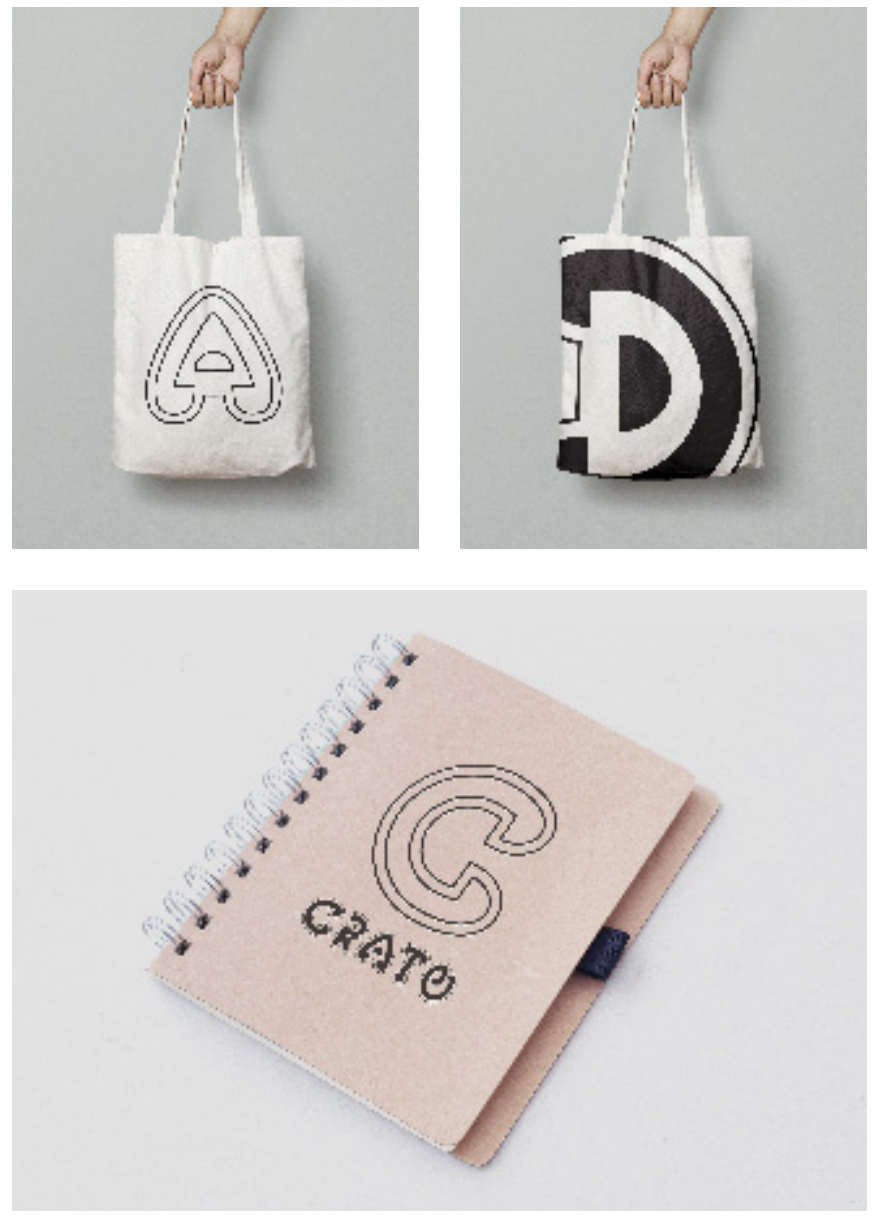

Fonte: Elaborada pela autora, 2016.

\section{CONSIDERACÕES FINAIS}

A elaboração da fonte tipográfica foi desafiadora, o contato da autora com a área gráfica, até então havia sido na realização de trabalhos de criação de cartazes eletrônicos, identidade visual e desenho de produtos. O resultado obtido e apresentado neste projeto é positivo dentro dos objetivos propostos, mas admite-se a necessidade de um aprofundamento em relação a formatação no design da fonte, no que se refere a inclinação das letras, a largura, o desenho dos números e os sinais de pontuação.

Sobre a pesquisa bibliográfica dos Índios Kariri, constatamos que são poucas as referências disponíveis, e que as informações encontradas foram base essencial para o desenvolvimento do trabalho. Entende-se o valor de investir na pesquisa histórica, na cultura e na região do Cariri Cearense.

Estudar tipografia, história da escrita, pesquisar trabalhos de alunos e professores de outras instituições e o desafio de criar e desenvolver a fonte tipográfica foram elementos inspiradores para o aprofundamento da pesquisa. 
Da mesma forma, pretende-se contribuir para instigar o interesse de estudantes de Design e pesquisadores das diversas áreas que se faça e promova o resgate da cultura local, regional.

\section{REFERÊNCIAS}

ALENCAR, Thalyta Cavalcante. Memória dos índios Kariris: as narrativas de remanescentes do Monte Alverne - Crato. 2014. 51 f. Trabalho de Conclusão de Curso (Graduação em Biblioteconomia) - Centro de Ciências Sociais Aplicadas, Universidade Federal do Cariri, Juazeiro do Norte, 2014.

AMBROSE, Gavin; HARRIS, Paul. Fundamentos do design criativo. Tradução de Edson Furmankiewicz. Porto Alegre: Bookman, 2009.

BARROSO, Gustavo. À margem da história do Ceará. 2. ed. Fortaleza: FUNCET, 2004.

CABARGA, Leslie. Logo, Font \& Lettering Bible. Palm Coast: How Design Books, 2004.

FACCIONE FILHO, Mauro. Legibilidade x leiturabilidade. Disponível em: <http://www.abraweb.com.br/index.php/artigos/legibilidade-xleiturabilidade>. Acesso em: 7 mar. 2016.

FIGUEIREDO FILHO, J. História do Cariri I. Fortaleza: Edições UFC, 2010. v. 1.

FINIZOLA, Maria de Fátima Waechter. Panorama tipográfico dos letreiramentos populares: um estudo de caso na cidade do Recife. 2010. Dissertação (Mestrado em Design e Ergonomia) -Universidade Federal de Pernambuco, Recife, 2010.

FRUTIGER, Adrian. Sinais e símbolos: desenho, projeto e significado. Tradução de Karina Jannini. 2. ed. São Paulo: Martins Fontes, 2007.

GOMES, Ricardo Esteves. O design brasileiro de tipos digitais: a configuração de um campo profissional. São Paulo: Blucher, 2010. (Coleção pensando o design). 
HORCADES, Carlos M. A evolução da escrita: história ilustrada. Rio de Janeiro: Senac Rio, 2004.

IBGE. Cidades. Ceará: Nova Olinda: histórico. Disponível em: <http://cidades. ibge.gov.br/painel/historico.php?lang $=\&$ codmun $=230920 \&$ search $=$ ceara|no va-olinda|infograficos:-historico>. Acesso em: 15 set. 2015.

LABORATÓRIO DE TIPOGRAFIA DO AGRESTE. Apresentação. Disponível em: <http://laboratoriodetipografia.com.br/agreste/contato/>. Acesso em: 10 jan. 2016.

LIMA, F. F. de et al. Geopark Araripe: histórias da terra, do meio ambiente e da cultura. Fortaleza: Governo do Estado do Ceará, Secretaria das Cidades, 2010.

LIMAVERDE, Rosiane. Acervo lítico e cerâmico da chapada do Araripe, Ceará, Brasil. Nova Olinda: Fundação Casa Verde, 2006. Disponível em: <http://www. fundacaocasagrande.org.br/pdf/acervo_litico_e_ceramico_do_cariri.pdf $>$. Acesso em: 12 ago. 2016.

LUPTON, Ellen; PHILLIPS, Jenifer Cole. Novos fundamentos do design. São Paulo: Cosac Naify, 2008.

MARTINS, Ana Claudia Oliveira; BUGGY, Leonardo Araújo da Costa; VIEIRA, Rosangela. Compilação de métodos para desenho tipográfico usados por designers recifenses. In: CONGRESSO BRASILEIRO DE PESQUISA E DESENVOLVIMENTO EM DESIGN, 10., 2012, São Luís. Anais... São Luís: P\&D Design, 2012.

MEMORIAL DO HOMEM CARIRI. Mitos e lendas. Nova Olinda: Fundação Casa Grande, [20--].

MEMORIAL DO HOMEM KARIRI. Disponível em: <https:// memorialdohomemkaririfcg.wordpress.com/>. Acesso em: 13 abr. 2015.

NIEMEYER, L. Tipografia: uma apresentação. 4. ed. Rio de Janeiro: 2 AB, 2006.

PINTEREST. O que é Pinterest? Imprensa. Disponível em: <https://about. pinterest.com/pt-br/press/press>. Acesso em: 10 jan. 2016.

SOUZA, Roger Paulino. Tipografia: a evolução da forma e da técnica. 2014. Disponível em: <https://www.youtube.com/watch?v=skySGQTc_Rg>. Acesso em: 17 nov. 2015. 
WONG, Wucius. Princípios de forma e desenho. Tradução de Alvamar Helena Lamparelli. 2. ed. São Paulo: WMF Martins Fontes, 2010.

Submissão: 09-2016

Aceite: 07-2017 